\title{
A trajetória da Educação Ambiental: dos eventos internacionais à elaboração da legislação e documentos oficiais no Brasil.
}

\author{
${ }^{1}$ Leonardo Dias Ariane Silva \\ ${ }^{2}$ Robson Luiz Calmon Costa
}

\begin{abstract}
Resumo- O objetivo central desse artigo é refletir sobre a crise ambiental contemporânea e os eventos históricos que contribuíram para a formação do campo epistemológico relativamente recente que é a Educação Ambiental, desde o pós-guerra até hoje. Consideramos ainda como esses processos se refletiram através dos documentos norteadores para a educação básica no Brasil, no plano legal e pedagógico, criando pilares fundantes para práticas educativas exitosas que transcendam o ecologismo clássico, agregando a dimensão política/social que envolve a prática docente desde a educação básica, visto que o enfrentamento da crise exige reflexão/ação de vários atores sociais que articulem a dimensão ética nas relações entre homem, natureza e sociedade.
\end{abstract}

Palavras Chave: Educação Ambiental. Crise Ambiental. Ecologia Humana.

Abstract- The main objective of this article is to reflect on the contemporary environmental crisis and the historical events that contributed to the formation of a relatively recent epistemological field that is Environmental Education, since the post-war period until today. We also consider how these processes were reflected in the guiding documents for basic education in Brazil, at the legal and pedagogical level, creating fundamental pillars for successful educational practices that transcend classic ecologism, adding the political/social dimension that involves teaching practice from basic education, since facing the crisis requires reflection/action of various social actors that articulate the ethical dimension in the relations between man, nature and society.

Key words: Environmental Education. Environmental Crisis. Human ecology.

\section{1- INTRODUÇÃO}

A temática ambiental, outrora restrita aos setores políticos e industriais, ganha cada vez mais visibilidade no cenário contemporâneo à medida que a degradação do ambiente aumenta a preocupação de todos com o futuro incerto de mudanças

\footnotetext{
${ }^{1}$ Mestre em Ciências da Educação pela Facultad Interamericana de Ciencias Sociales (FICS). Especialista em Educação Ambiental pela Universidade Federal da Bahia (UFBA) e Educação de Jovens e Adultos (EJA) pela Faculdade Venda Nova do Imigrante (FAVENI). Gestor da Prefeitura Municipal de Salvador, professor da Secretaria da Educação do Estado da Bahia e tutor pela UNEFEaD. E-mail: leonardo.ariane@gmail.com
}

${ }^{2}$ Mestre em Ciências da Educação pela Fics- 2020; Especialista em Gestão Ambiental pela Universidade Gama Filho- 2011; Especialista em Metodologia de Ensino na Educação Superior Faculdade Visconde de Cairu- 2007; Professor de Ciências Naturais e Biologia da Secretaria da Educação do Estado da Bahia no Colégio Estadual Anfrísia Santiago Salvador-Ba; Professor de Ciências Naturais da Prefeitura Municipal do Salvador na Escola Municipal Padre Norberto, SalvadorBa. E-mail: nosborcalcost@hotmail.com.br; nosborcalcost@gmail.com 
climáticas, perda da biodiversidade, diminuição da qualidade de vida e escassez de recursos naturais sem precedentes.

A constatação cada vez mais evidente dessa realidade, estimulou a construção de uma abordagem epistemológica na qual a reflexão acerca das práticas existentes, redefina as múltiplas possibilidades para uma nova racionalidade que articule equilíbrio entre natureza, técnica e cultura com o objetivo de promover um caminho possível para a sustentabilidade da vida na Terra.

Esse trabalho tem por objetivo discutir o contexto contemporâneo da Educação Ambiental(EA) no Brasil, os eventos históricos que resultaram no surgimento e na inserção da Educação Ambiental na pauta do dia, além de destacar alguns marcos legais que regulamentam a prática obrigatória do seu ensino em todos os níveis.

Existe um paradoxo da sociedade contemporânea ao afirmar a importância da preservação da natureza ao mesmo tempo que apresenta padrões de comportamento e consumo incompatíveis com os recursos finitos do planeta. Assim, essa pesquisa se justifica, pois, destina-se a analisar as bases educacionais no Brasil e seu papel no enfrentamento da crise ambiental.

A crise ambiental exige mudança nos modelos de ensino, desenvolvimento, produção e consumo. Para alcançar essa transição os caminhos traçados deverão, em primeira instância, passar pelo plano educacional. Um processo educativo pautado nos princípios da EA deve criar uma perspectiva emancipatória a partir da qual o educando entenda seu protagonismo social e a responsabilidade de atuação do poder público.

A pesquisa realizada a partir de revisão bibliográfica, permitiu obter um panorama mais claro sobre os eventos históricos que resultaram na Educação Ambiental moderna com seus aspectos epistemológicos e legais. Além disso, analisamos alguns eventos no Brasil e no mundo e seus reflexos na legislação e nos documentos norteadores para a prática docente na educação básica. Esse arcabouço teórico é importante porque torna possível construir reflexões/ações positivas para a Educação Ambiental no Brasil, correlacionando o plano pedagógico com as políticas públicas vigentes. 


\section{DESENVOLVIMENTO}

\subsection{A evolução histórica da Educação Ambiental.}

O mundo pós-guerra exigia demanda crescente de insumos para sua reconstrução, exercendo pressão cada vez maior nos recursos naturais, além de degradação ambiental principalmente nos países ricos. No ano de 1968, em Roma, ocorreu um encontro para discutir as consequências do modelo de desenvolvimento vigente nos países desenvolvidos e desejado pelos emergentes. Sob os auspícios da ONU o resultado dessa discussão foi a publicação, em 1972, do relatório "Os limites do crescimento", no qual se projetavam perspectivas ominosas para o futuro caso não mudássemos os paradigmas de crescimento, em óbvio descompasso com os limites ecológicos do planeta.

Durante a década de 1960 começaram de forma difusa e aparentemente desarticulada entre si manifestações que questionavam o modelo capitalista de produção. Antes da formação do clube de Roma, Carson (1962) publicou o livro Silent spring (Primavera silenciosa), cuja leitura acessível levou a temática ambiental ao grande público. Movimentos de contracultura em países ricos e em desenvolvimento, se opunham à cultura hegemônica vigente. $O$ capitalismo e o estilo de vida consumista já encontravam oposição entre os hippies, os beatniks, os jovens organizados nos movimentos estudantis, os espiritualistas e os pacifistas. Cada um desses elementos com suas características peculiares contribuiu para o fortalecimento do movimento que culminaria nos anos à frente na colocação da Educação Ambiental ${ }^{3}$ na pauta do dia (GONÇALVES, 1998).

Apesar da diversidade de origem desses grupos heterogêneos havia um elo de ligação bem definido: a rejeição dos padrões gerados pelo sistema capitalista. Nesse contexto, podemos dizer que surgia um horizonte mais acolhedor para a Educação Ambiental porque fatores sociais, econômicos, políticos e culturais estavam contribuindo para a formação de uma consciência ambiental questionadora que

\footnotetext{
${ }^{3}$ O termo Educação Ambiental (Environmental Education), foi adotado em 1965 durante a conferência de Educação da Universidade de Keele, Grã-Bretanha (DIAS, 2002).
} 
problematizava as relações entre sociedade e meio ambiente, além de promover o reconhecimento da questão ambiental no mundo ocidental (LIMA, 2011, p. 33).

Com o avanço da degradação ambiental em várias partes do mundo e movimentos crescentes em defesa do ambiente se estruturando cada vez mais, a temática ambiental ganhou força. Em 1972, na cidade de Estocolmo, houve a Conferência das Nações Unidas sobre Meio Ambiente. Foi um marco histórico importante, pois contribuiu para o processo de formação da Educação Ambiental ao deslocar a temática ambiental para o centro de discussões políticas e empresariais relevantes, transcendendo o caráter estético ao qual o pensamento ecológico ficou restrito por algum tempo.

A "Conferência de Estocolmo", como ficou conhecida, sugeriu um programa internacional para a Educação Ambiental, criado em 1975. A "Carta de Belgrado" recomendava a necessidade de preservar os recursos naturais para as gerações atuais e futuras conferindo forma e conteúdo a emergente Educação Ambiental no cenário mundial. Além disso, esse documento questionava as políticas de crescimento que não levassem em consideração o ambiente e a perda da qualidade de vida.

A abordagem proposta para a resolução da crise ambiental foi entendida como uma expressão dos interesses de países centrais, haja visto que no Brasil haveriam outras prioridades, segundo a perspectiva dos militares no poder. Essa falta de discernimento sobre a relevância da preservação do ambiente permaneceu firme até os anos 80 quando houve uma aproximação do discurso ambientalista com os setores desenvolvimentistas.

Como produto síntese desse movimento, o Relatório Our Commom Future (Nosso Futuro Comum), publicado em 1987 pela ONU preconizava a utilização dos recursos naturais como base para o próprio desenvolvimento. Nesse contexto, Brundtland (1991, p. 01), afirma:

[...] vemos, ao contrário a possibilidade de uma nova era de crescimento econômico, que tem de se apoiar em práticas que conservem e expandam a base de recursos ambientais. E acreditamos, que tal crescimento é absolutamente essencial para mitigar a grande pobreza que se vem intensificando na maior parte do mundo em desenvolvimento.

O contexto político e social brasileiro da época não se mostrou acolhedor ao discurso emergente da EA, sob a alegação que isso congelaria as desigualdades enormes entre países ricos, pobres e emergentes. Os baixos índices de 
desenvolvimento humano nacionais colaboraram para a rejeição da temática ambiental como um item desnecessário à realidade brasileira.

O arrefecimento de segmentos conservadores ligados ao Capital contra a questão ecológica decorreu do alinhamento do discurso ambientalista com a redução da pobreza. Até então, muitos direcionamentos do discurso ambientalista eram dotados de um maniqueísmo, segundo o qual deveríamos optar pelo desenvolvimento econômico ou qualidade de vida e do ambiente. O relatório Nosso Futuro Comum propôs um discurso equilibrado que reconhecia a necessidade de usar os recursos naturais de maneira sustentável como meio de desenvolvimento.

O Brasil começou a superar alguns entraves relacionados ao modelo de desenvolvimento adotado pelos militares, claramente indiferentes a questão ambiental. Nesse contexto, houve um encontro internacional no Rio de Janeiro, conhecido como Cúpula da Terra ${ }^{4}$, que resultou na Agenda 21. Segundo Sorrentino (1998), esse protocolo preconizava ações que deveriam ser aplicadas a fim de enfrentar a crise ecológica, colocando definitivamente o país no epicentro das discussões mundiais sobre a Educação Ambiental.

O país ainda se acostumava com a redemocratização que trouxe oportunidade de crescimento a partir do diálogo com amparo da Constituição de 1988. O atraso resultante da posição dos governos militares para a questão ambiental ainda exigia ações que se materializaram nesse encontro. Um dos legados que a Rio-92 deixou foi a recomendação da preservação da Biodiversidade enquanto patrimônio da humanidade e a Agenda 21, que configurava um conjunto de 40 ações para as nações implementarem um modelo de desenvolvimento sustentável para o século 21.

Essas ações se efetivadas de maneira adequada deveriam diminuir as injustiças sociais e aprimorar a eficiência econômica mundial. Para o Brasil esse encontro era emblemático, pois representava a nova configuração social que o país assumia no cenário global após o retrocesso sofrido durante a ditadura militar.

\footnotetext{
${ }^{4}$ Esse encontro ficou conhecido também como ECO-92, Rio-92 e Cimeira de verão.
} 


\subsection{Referenciais teóricos e legais para Educação Ambiental no Brasil.}

As articulações para implantação da EA no Brasil eram promissoras quando foi criada, em 1973, a Secretaria Especial de Meio Ambiente (SEMA) vinculada ao Ministério do Interior que introduz formalmente a EA no país. A probabilidade de resultar num órgão inerte, sem nenhum efeito prático como é costume no Brasil, parecia eminente, pois contava apenas com três funcionários. Entretanto, a atitude abnegada deles sob liderança do professor Paulo Nogueira Neto, entre 1973 e 1986, tornaram a SEMA reconhecida internacionalmente e lançaram as bases que normatizam as leis ambientais brasileiras. Conforme Dias (2004) aponta, a criação da SEMA se tratava de uma resposta do regime as pressões do Banco Mundial e de instituições Ambientalistas que já atuavam no país e se intensificaram após o encontro em Estocolmo.

Já em 1981, a Lei no 6.938 que institui a Política Nacional do Meio Ambiente, determinou a inserção da Educação Ambiental em todos os níveis de ensino. Concordamos que representou grande avanço porque estabelece no Art. $2 \S \mathrm{X}$ [...] "a educação da comunidade, objetivando capacitá-la para participação ativa na defesa do meio ambiente". Esse contexto garantia aos docentes o direito de estimular o protagonismo social dos indivíduos e das comunidades através da prática pedagógica com autonomia que não era possível durante os períodos mais intensos da ditatura militar.

Um dos pilares fundantes da EA desde seus estágios iniciais de desenvolvimento era um entendimento mais abrangente de Ambiente que fosse além dos fatores ambientais e dos seres vivos. Para entender a imbricada rede de relações naturais e antrópicas (culturais, sociais, econômicas, políticas e éticas) que se estabelecem e interferem no ambiente é necessária uma abordagem integradora, na qual o elemento humano seja reconhecido como integrante da própria natureza.

A conferência de Tbilisi em cooperação com o Programa das Nações Unidas para o meio Ambiente (PNUMA), estimula uma perspectiva de análise mais dialética considerando todo o contexto dos problemas ambientais, a partir do elo que une aspectos políticos, sociais, econômicos e ecológicos. Qualquer abordagem que não considere essas relações não pode ser considerada ambientalmente sustentável. 
A EA conduz ao entendimento que não podemos dissociar o homem da natureza. Compomos o tecido da vida como elementos naturais, mas ao mesmo tempo gozamos de situação diferenciada das demais espécies pela capacidade de refletir sobre nossas ações sobre o ambiente. Diante disso, o termo problema socioambiental tem sido adotado ultimamente porque reflete a compreensão que sociedade e natureza são partes interligadas.

O Ministério da Educação e Cultura (MEC), enquanto órgão responsável pela orientação das diretrizes educacionais do país, ignorou os direcionamentos mundiais relacionados à EA durante o período das ditaduras militares. Houve, restrições aos programas nacionais que tentavam aprofundar as discussões sobre o ambiente. Dessa forma articulou-se no Brasil a uma abordagem reducionista que só melhorou após a Constituição Federal de 1988.

Entre ranços e avanços a EA não parou de evoluir no Brasil e no mundo. O MEC não conseguiu organizar uma proposta eficiente para promoção dos princípios da EA no sistema educacional brasileiro. Na verdade, se o MEC não estabelece ações claras para a educação em geral quanto mais para atender as especificidades da EA.

Apesar disso, em 1998 o MEC publicou os Parâmetros Curriculares Nacionais (PCN's) que estabelecem as diretrizes para a Educação no Brasil e apontam para a necessidade de superar a abordagem fragmentada da questão ambiental, ao salientar que:

\begin{abstract}
Para que os alunos construam a visão da globalidade das questões ambientais é necessário que cada profissional de ensino, mesmo especialista em determinada área do conhecimento, seja um dos agentes da interdisciplinaridade que o tema exige. A riqueza do trabalho será maior se os professores de todas as disciplinas discutirem e, apesar de todo tipo de dificuldades, encontrarem elos para desenvolver um trabalho conjunto. Essa interdisciplinaridade pode ser buscada por meio de uma estruturação institucional da escola, ou organização curricular, mas requer, necessariamente, a procura da superação da visão fragmentada do conhecimento pelos professores especialistas (BRASIL, 1998, p. 193).
\end{abstract}

A lei n. 9.795, de 27 de abril de 1999, assinada pelo então presidente da república Fernando Henrique Cardoso, dispõe sobre a educação ambiental brasileira da seguinte maneira:

Art. 1. - Entendem-se por educação ambiental os processos por meio dos quais o indivíduo e a coletividade constroem valores sociais, conhecimentos, habilidades, atitudes e competências voltadas para a conservação do meio ambiente, bem de uso comum do povo, essencial à sadia qualidade de vida e sua sustentabilidade (BRASIL, 1999, p. 1). 
Apesar dos intensos debates de grupos antagônicos no plano político e educacional durante o processo de construção da Base Nacional Comum Curricular (BNCC), a educação ambiental permaneceu como pauta relevante na educação formal desde os anos iniciais de escolarização. No décimo item, relacionado à construção de competências para a educação básica, temos destacados como elementos fundamentais para tomada de decisão "[...] princípios éticos, democráticos, inclusivos, sustentáveis e solidários" (BRASIL, 2017, p. 10, grifo nosso).

Ao analisar o conteúdo das leis e documentos orientados mencionados até aqui que organizam o ensino da EA no Brasil encontramos pontos de convergência com os referenciais formulados nos encontros internacionais com destaque para o princípio da participação coletiva e individual.

A dimensão dos problemas ambientais não pode satisfazer-se com respostas simples porque o reducionismo não pode responder satisfatoriamente um problema com múltiplas origens. Ao encontro desse pensamento Freire (1996) afirma que o professor deve ser capaz de organizar os diferentes saberes e usá-los para estimular sua produção ou mesmo construção. Desse modo, neutralidade e indiferença não são opções válidas se queremos promover mudanças reais não apenas no campo educacional, mas, ao promover mudanças nesse plano, criar circunstâncias que ajudem os alunos/cidadãos para atuação em conformidade com o modelo de sociedade mais justo e sustentável que desejamos.

Assim, acreditamos que a atividade docente corretamente articulada com os princípios e práticas da EA, pode ser um elemento catalisador de ações exitosas de transformação da realidade desfavorável com a qual têm sido tratadas as questões ambientais.

\section{Considerações finais}

A mudança necessária referente a crise ambiental não ocorrerá com pequenas ações isoladas desse ou daquele grupo social, governo ou de Organizações não Governamentais (ONG's). Tampouco poderá acontecer sem a participação destes. Antes, devemos perceber que todos os segmentos da sociedade civil organizada deverão, cada um na sua esfera de atuação, colaborar para a mudança do paradigma atual que tem resultado degradação do ambiente. 
É fundamental desenvolver um novo modelo socialmente sustentável no qual as pessoas entendam seu papel no seu contexto social e as relações com a situação planetária. Nesse contexto o docente deve estimular através da prática pedagógica a responsabilidade para agir em benefício do bem-estar coletivo. Esse modelo não acontecerá sem um projeto de educação que oriente essa construção no plano político-pedagógico, porque não é mais possível pensar em desenvolvimento de qualquer natureza sem agregar valores socioambientais que norteiem sua implantação e execução.

Em harmonia com a vinculação entre educação e sociedade, uma proposta de ensino inovadora exige o engajamento docente cuja atuação não deve caminhar independente da estrutura legal das políticas públicas vigentes, algumas das quais discutidas ao longo desse trabalho, antes, em conformidade com elas. Ao mesmo tempo deve sugerir mudanças estruturais que colaborem com a construção de novos caminhos possíveis para um mundo sustentável.

Observamos que o Brasil conta com um conjunto de leis sólidas que estruturam e validam o ensino e a prática de ações em defesa do ambiente e da sustentabilidade. Além disso, no plano pedagógico existem documentos orientados que garantem a autonomia docente para a promoção de princípios éticos relacionados ao ensino da Educação Ambiental em todos os níveis. Assim, acreditamos que o caminho para um projeto exitoso de mudança em relação ao ambiente está em curso, embora ainda haja muito a ser feito.

A crise ambiental está no centro das relações entre sociedade e natureza, e qualquer solução para o enfrentamento da crise deve ser abordada a partir da perspectiva, na qual a natureza e sociedade devem ser consideradas em igualdade de relevância. Não há possibilidade de futuro seguro sem assegurar a integridade da própria mantenedora dos recursos que asseguram a vida, a saber - a natureza. 


\section{REFERÊNCIAS:}

BRASIL, Diário Oficial da União Lei no 6.938, de 31 de agosto de 1981. Dispõe sobre a Política Nacional do Meio Ambiente, seus fins e mecanismos de formulação e aplicação, e dá outras providências. Brasília, 1981.

BRASIL, Ministério da educação e do desporto. Secretaria de Educação Fundamental: Introdução aos temas transversais. Parâmetros Curriculares Nacionais: Ciências Naturais. - Brasília MEC / SEF, 1998.

BRASIL. Ministério da Educação. Base Nacional Comum Curricular. Terceira Versão. Brasília: MEC, 2017.

BRUNDTLAND, G. H. Nosso futuro comum: comissão mundial sobre meio ambiente e desenvolvimento. 2 ed. Rio de Janeiro: Fundação Getúlio Vargas, 1991.

CARSON, R. Primavera Silenciosa. Boston: Houghton Mifflin, 1962.

DIAS, G. F. Educação Ambiental: princípios e práticas. 7 ed. revista e ampliada. São Paulo: Gaia, 2004.

DIAS, G. F. Pegada ecológica e sustentabilidade humana. São Paulo: Gaia, 2002.

FREIRE, P. Pedagogia da Autonomia: saberes necessários à prática educativa. São Paulo: Paz e Terra, 1996.

GONÇALVES, C. W. D. Os (Des)caminhos do meio ambiente. 6 ed. São Paulo: Contexto, 1998.

LIMA, G. F. C. Educação Ambiental no Brasil: Formação, identidades e desafios. Campinas, São Paulo. Papirus, 2011.

SORRENTINO, M. De Tbilisi a Tessaloniki, a educação ambiental no Brasil. In: JACOBI, P. et al. (orgs.). Educação, meio ambiente e cidadania: reflexões e experiências. São Paulo: SMA,1998. 